\title{
Calcium phosphate cement augmentation of cancellous bone screws can compensate for the absence of cortical fixation
}

\author{
Vincent A. Stadelmann ${ }^{\mathrm{a}, \mathrm{b}}$, Elise Bretton ${ }^{\mathrm{a}}$, Alexandre Terrier ${ }^{\mathrm{a}}$, Philip Procter ${ }^{\mathrm{c}, \mathrm{d}}$, Dominique P. Pioletti ${ }^{\mathrm{a}, *}$ \\ ${ }^{a}$ Laboratory of Biomechanical Orthopedics, Institute of Bioengineering, EPFL, EPFL/STI/IBI/LBO, Station 15, 1015 Lausanne, Switzerland \\ ${ }^{\mathrm{b}}$ Laboratory of Bone Imaging, Schulich School of Engineering, University of Calgary, Canada \\ c Stryker Osteosynthesis, Selzach, Switzerland \\ d School of Engineering and Design, Brunel University Uxbridge, UK
}

\section{A R T I C L E I N F O}

\section{Article history:}

Accepted 21 July 2010

\section{Keywords:}

Screw fixation

Pullout force

Calcium phosphate cement

Osteoporotic bone

\begin{abstract}
A B S T R A C T
An obvious means to improve the fixation of a cancellous bone screw is to augment the surrounding bone with cement. Previous studies have shown that bone augmentation with Calcium Phosphate (CaP) cement significantly improves screw fixation. Nevertheless, quantitative data about the optimal distribution of CaP cement is not available. The present study aims to show the effect of cement distribution on the screw fixation strength for various cortical thicknesses and to determine the conditions at which cement augmentation can compensate for the absence of cortical fixation in osteoporotic bone. In this study, artificial bone materials were used to mimic osteoporotic cancellous bone and cortical bone of varying thickness. These bone constructs were used to test the fixation strength of cancellous bone screws in different cortical thicknesses and different cement augmentation depths. The cement distribution was measured with microCT. The maximum pullout force was measured experimentally. The microCT analysis revealed a pseudo-conic shape distribution of the cement around the screws. While the maximum pullout strength of the screws in the artificial bone only was $30 \pm 7 \mathrm{~N}$, it could increase up to approximately $1000 \mathrm{~N}$ under optimal conditions. Cement augmentation significantly increased pullout force in all cases. The effect of cortical thickness on pullout force was reduced with increased cement augmentation depth. Indeed, cement augmentation without cortical fixation increased pullout forces over that of screws without cement augmentation but with cortical fixation. Since cement augmentation significantly increased pullout force in all cases, we conclude that the loss of cortical fixation can be compensated by cement augmentation.
\end{abstract}

(c) 2010 Elsevier Ltd. All rights reserved.

\section{Introduction}

Osteosynthesis plates and screws are used in combination to fix complex fractures. These metallic fixation systems are used with success in healthy bone. But when bone is weak and sizable stresses are present at the bone screw interface, the screw fixation may fail. In particular for osteoporotic bone, screw loosening is regularly observed (Kim et al., 2001; Seebeck et al., 2005; Simpson et al., 1989). Indeed two aspects limit screw fixation in osteoporotic bone. First, reduced quality of the trabecular bone structure impairs good stability of the screw (Seebeck et al., 2005). Second, the cortical bone layer has been shown to play a critical role in the screw holding power (Halvorson et al., 1994; Seebeck et al., 2005). In severely osteoporotic bones, the cortical layer is so weak that it cannot be preserved during surgery, compromising even more the fixation of the screw. Therefore,

\footnotetext{
* Corresponding author. Tel.: +4121693 8341; fax: +41216938660.

E-mail address: Dominique.pioletti@epfl.ch (D.P. Pioletti).
}

osteoporotic bone requires specific care to improve the performance of fixation devices (Cook et al., 2004).

An obvious means to improve the fixation of a cancellous bone screw is to augment the surrounding bone with cement. Augmenting bone with cement has been used in fracture fixation since the use of polymethylmethacrylate (PMMA) was proposed in 1962 (Benum, 1977; Mueller, 1962). Clinical studies have demonstrated that the adequate use of PMMA cement provides rapid weight-bearing stability to the fracture fixation (Bartucci et al., 1985; Muhr et al., 1979). However, bone augmentation with PMMA has well-known drawbacks such as poor biocompatibility, exothermic polymerization, and non-resorbability (Enis et al., 1974; Leeson and Lippitt, 1993). PMMA is being progressively abandoned and osteoconductive cements, such as calcium phosphate (CaP) cements, are becoming more popular in orthopedics and traumatology (Kawagoe et al., 2000). The mechanical properties of available CaP cements have been improved over the years. In a recent review by Larsson (2010), the compressive strength of a variety of currently available cements was reported and these have compressive strengths that are typically better than good quality cancellous bone. Despite 
these interesting mechanical properties, cements are approved in both Europe and USA as non-load bearing void fillers and are not intended for use in situations where they are intrinsic to the strength of the void. The strength aspect is always taken care of by implant such as plates and screws so the cement is not loaded at all in these applications. These cements have potential applications in bone defect filling, drug delivery, and osteosynthetic screw reinforcement. Previous studies have shown that bone augmentation with CaP cement significantly improves screw fixation. Van Landuyt et al. (1999) have reported a 3.3-fold increase in trabecular osteosynthesis strength when manually augmenting surrounding bone with brushite cement. Using harvested lumbar vertebrae implanted with pedicle screws, Rohmiller et al. (2002) have reported that cement augmentation increased pedicle screw pullout strength by $167 \%$ over the native bone.

It is known that screw fixation strength depends upon the screw geometry, the bone quality, the cortical thickness, and the insertion technique (Chapman et al., 1996; Halvorson et al., 1994; Seebeck et al., 2005). Additionally whilst it is known that screw fixation is influenced by the addition of cement, quantitative data about the optimal distribution of cement is yet not available.

Therefore, the present study aims to quantify the effect of cement distribution on the screw fixation strength for various cortical thicknesses and to determine the conditions at which cement augmentation can compensate for the absence of cortical fixation in osteoporotic bone.

\section{Materials and methods}

\subsection{Experimental design}

Material bone substitutes were used and assembled to mimic osteoporotic cancellous bone and cortical bone. Polyurethane foam was chosen for the cancellous part and a polyurethane resin was chosen for the cortical part. These constructs were used to measure the fixation strength of cancellous bone screw with different cortical thicknesses and different cement augmentation depths. The specimens were randomly separated into two groups: (I) with cortical fixation and (II) without cortical fixation. The group without cortical fixation was obtained by removing the cortical layer surrounding the screw. In each group, the following conditions were tested: cortical thicknesses of 1,2 , and $3 \mathrm{~mm}$ and augmentation depths of $0,5,10$, and $15 \mathrm{~mm}$ (Table 1 ).

\subsection{Material construct as an in vitro model of bone}

The cancellous part of the model was made of Sawbones, an open cell polyurethane rigid foam (ref \#1522507, Sawbones, Malmö, Sweden; density: $0.12 \mathrm{~g} / \mathrm{cm}^{3}$; compressive modulus: $18.6 \mathrm{MPa}$ ). The cell structure of this material is over $95 \%$ open pore and the pore size is $2+0.5 \mathrm{~mm}$. The cortical material was made with Cibatool, a polyurethane resin block (Cibatool BM 5166, Astorit, Einsiedeln, Switzerland; density: $1.7 \mathrm{~g} / \mathrm{cm}^{3}$, compressive modulus: $7.5 \mathrm{GPa}$ ). The material densities and mechanical properties are close to that of osteoporotic trabecular and cortical bone, respectively (Cowin, 2001).

\section{Table 1}

Experimental design matrix. The specimens were separated into two groups: (I) with cortical fixation and (II) without cortical fixation. In each group, the following conditions were tested: cortical thicknesses (Ct.th) of 1, 2, and $3 \mathrm{~mm}$ and augmentation depths (AD) of 0, 5, 10, and $15 \mathrm{~mm}$, respectively. Each condition was repeated 5-7 times.

\begin{tabular}{|c|c|c|c|c|c|c|c|}
\hline \multicolumn{2}{|c|}{ Ct.th: } & \multicolumn{3}{|c|}{ (I) With cortical fixation } & \multicolumn{3}{|c|}{ (II) Without cortical fixation } \\
\hline & & 1 & 2 & 3 & 1 & 2 & 3 \\
\hline \multirow[t]{4}{*}{ AD } & $\mathbf{0}$ & 6 & 6 & 6 & 6 & 5 & 6 \\
\hline & 5 & 6 & 6 & 7 & 6 & 6 & 7 \\
\hline & 10 & 5 & 6 & 7 & 6 & 7 & 7 \\
\hline & 15 & 5 & 6 & 6 & 6 & 6 & 6 \\
\hline
\end{tabular}

The bone models were made of foam blocks of $20 \times 20 \times 40 \mathrm{~mm}^{3}$ and resin disks of $20 \mathrm{~mm}$ in diameter and 1, 2, or $3 \mathrm{~mm}$ in thickness. For the group (I) with cortical fixation, a hole of $3.4 \mathrm{~mm}$ diameter was predrilled in the disk resin, allowing the screw thread to be engaged in the resin. For the group (II) without cortical fixation, the diameter of the hole was $5 \mathrm{~mm}$, and the thread was therefore not engaged in the resin. The disks were placed on top of the foam blocks and maintained with adhesive tape. A hole with a diameter of $2.7 \mathrm{~mm}$ and a depth of $20 \mathrm{~mm}$ was drilled perpendicular to the constructs with the machine drill set to $600 \mathrm{rpm}$ at the center of each block. A linearly guided machine drill was used to align the drill axes perpendicular to the resin surface. The drilling depth was controlled with a precision ruler wrapped around the drill.

\subsection{Cementing and screwing protocols}

Specimens with $0 \mathrm{~mm}$ of augmentation depth were not cemented at all. All the other specimens were augmented with Calcium Phosphate (CaP) cement Hydroset $^{\mathbb{R}}$ (Stryker Osteosynthesis, Selzach, Switzerland).

To obtain the augmentation depths of 5,10 , and $15 \mathrm{~mm}$, custom-built cylindrical steel plugs of $2.7 \mathrm{~mm}$ in diameter and 15,10 , and $5 \mathrm{~mm}$ in length, respectively, were inserted in the drilled holes prior to cement injection (Fig. 1a). These plugs had extensions of $30 \mathrm{~mm}$ length and $1 \mathrm{~mm}$ in diameter directed upward, allowing the plugs to be removed later. The cement was used following the manufacturer's instructions at $19 \pm 0.5^{\circ} \mathrm{C}$ as the cement is designed for use in an operating room environment $\left(18-22^{\circ} \mathrm{C}\right)$. Briefly, the powder and the solution were hand mixed during $45 \mathrm{~s}$. The compound was then transferred to the syringe, a cannula was fixed on the syringe and a rubber ring was fixed at the end of the cannula to avoid leakages. The cement was then injected manually at low speed until the predrilled hole was full (Fig. 1b). A custom-made depressor was used to uniform the distribution of the cement in the hole. It is a $25 \mathrm{~mm}$-long cylinder of $2.65 \mathrm{~mm}$ in diameter with a hole of $1.3 \mathrm{~mm}$ in the center. The depressor was placed on the plug extension and moved downward until resistance was found. Then the plug and the depressor were removed manually (Fig. 1c). A package of cement contains enough powder subcomponents and liquid solution to inject three specimens.

Titanium non-cannulated cancellous screws of $4 \mathrm{~mm}$ in diameter by $35 \mathrm{~mm}$ (ref: 604035, Stryker Osteosynthesis, Selzach, Switzerland; core diameter: $2.4 \mathrm{~mm}$, thread pitch: $1.75 \mathrm{~mm}$ ) were inserted with a manual screwdriver until a depth of $20 \mathrm{~mm}$ (Fig. 1d). The depth was controlled with a $5 \mathrm{~mm}$ plastic ring placed under the screw head: the insertion was stopped when the ring touched the resin disk and the ring was removed. This space was kept for two reasons: first it avoids damages due to the pressure of the head on the resin, and the resultant pressure in the foam; second, it allows to standardize the clamping of the screw head during the pullout tests. After the screw insertion, the specimens were kept in an incubator during 3 days at $37{ }^{\circ} \mathrm{C}, 90 \%$ of humidity to let the cement set in conditions similar to those found in-vivo.

\subsection{Scanning}

After the 3 days incubation period, each specimen was scanned to assess the cement distribution and screw positioning. To ensure the permanent humidity of the cement, the samples were first wrapped in plastic conservation paper (Freshstar, Migros, Switzerland). The screw head was then clamped in a specially designed screw holding sleeve to ensure the alignment of the screw with the scanning axis. The holding sleeve was then placed in the polystyrene support of the $\mu \mathrm{CT}$ (SkyScan1076, SkyScan, Belgium). Each scan was performed with a beam of $90 \mathrm{kV}$ and $110 \mathrm{~A}$ with a $1 \mathrm{~mm}$ aluminum filter. The pixel size was $18 \mu \mathrm{m}$ rotation step was $0.6^{\circ}$ over $360^{\circ}$, exposure time was $400 \mathrm{~ms}$, and each image was averaged three times. At the beginning of each scanning session and after every four specimens, a flat-field correction was performed to reduce the signal to noise ratio, and ensure a constant exposure of the images. The dataset was reconstructed on the $\mu \mathrm{CT}$ software with constant parameters following manufacturer's recommendations. The $\mu \mathrm{CT}$ analysis was done with CTAN (SkyScan, Belgium) The screw position was controlled visually, and specimens with non-aligned screws were discarded. Fixed thresholds were defined to separate the cement from the screw and foam. A custom macro was used to measure the cement volume and the axial augmentation.

\subsection{Pullout force}

The specimens were mounted on an Instron Microtester 5848, (Instron, MA, USA) equipped with a $100 \mathrm{~N}$ gage. A custom-made clamping system was developed to adequately link the screw head to the testing machine's jack, and a rigid steel plate with a hole of $15 \mathrm{~mm}$ was mounted on the resin disk to retain the specimen in the fixture system. The screw was pulled out until failure using a displacement rate of $5 \mathrm{~mm} / \mathrm{min}$ (Fig. 1e). The load and the displacement were recorded at a sampling frequency of $100 \mathrm{~Hz}$. The mechanical test was stopped after complete separation of the screw from the specimen. The maximum force and the 


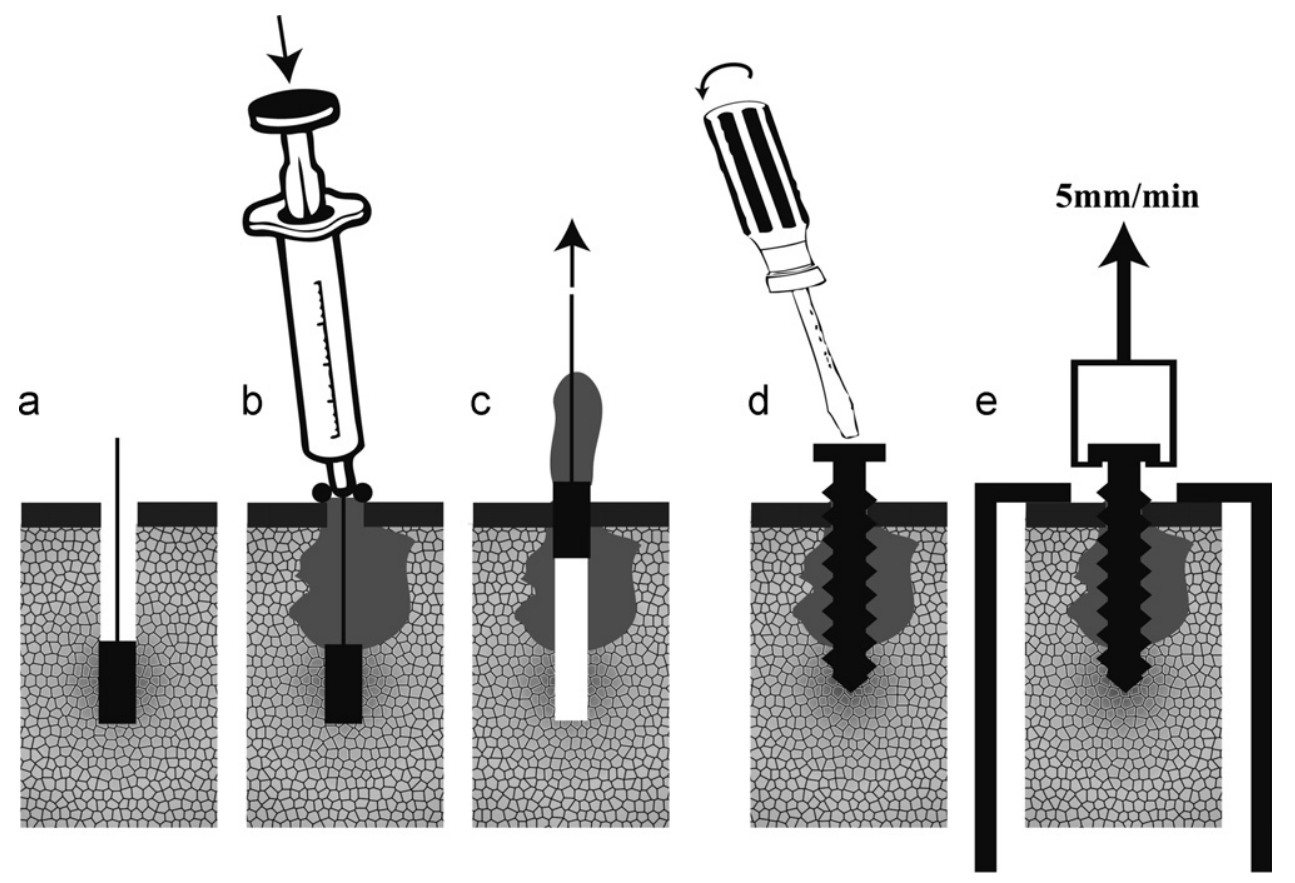

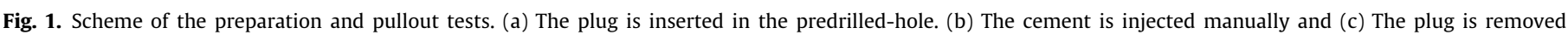

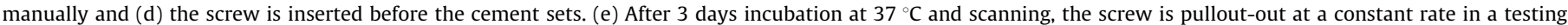
machine.
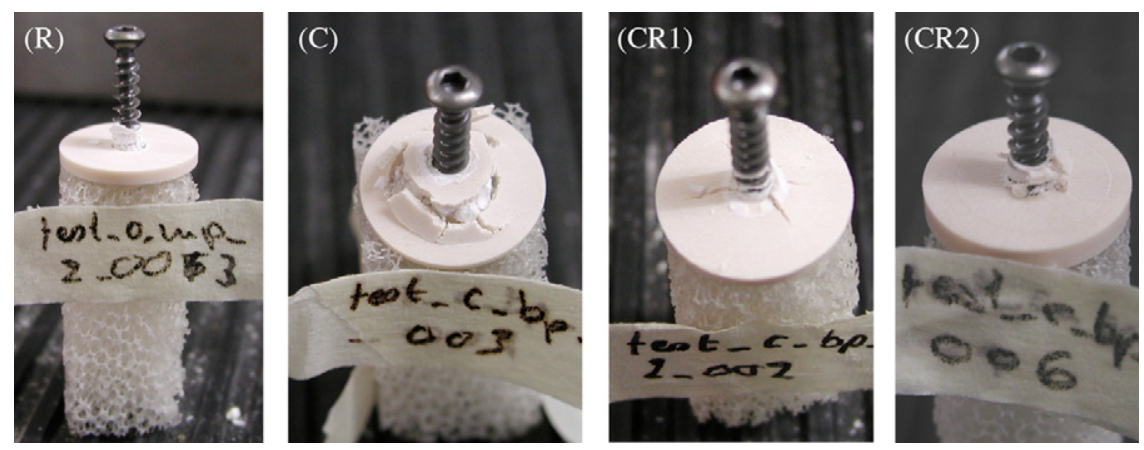

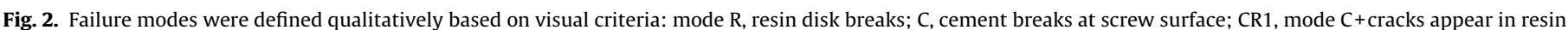
disks without failure; CR2, mode C+resin disks thread break without crack propagation.

stiffness were calculated from the force-displacement data with custom routines developed in Mathematica ${ }^{\mathbb{R}}$ (WolframResearch, Inc. USA).

\subsection{Failure modes}

The observed failure modes were defined qualitatively after visual criteria as shown in Fig. 2.

\subsection{Statistical design of the study}

The study was designed as full factorial with 6 repetitions of the measurements. Analysis of variance (ANOVA) was calculated to determine if cement augmentation, cortical thickness, or cortical fixation influenced the pullout forces. Bonferroni posthoc tests were performed to compare group means.

\section{Results}

\subsection{Cement distribution}

The $\mu \mathrm{CT}$ analysis revealed that the distribution of the cement around the screw had a pseudo-conic shape. The measured augmentation depths were $6.0 \pm 0.9 \mathrm{~mm}, 9.5 \pm 1 \mathrm{~mm}$, and
$15.3 \pm 1.7 \mathrm{~mm}$ with 15,10 , and $5 \mathrm{~mm}$ plug, respectively (Fig. 3a-c). The cement penetrated in the foam cells in all directions around the screw position (Fig. 3d). The augmentation depth and corresponding cement volume were well controlled with the developed technique (Fig. 3d,e). The distributions of cement in group I (with cortical fixation) and II (without cortical fixation) were not significantly different.

\subsection{Pullout forces}

While the holding strength of the screw in foam (group II, $\mathrm{AD}=0$ ) was only $30 \pm 7 \mathrm{~N}$, some combinations of conditions produced strengths of approximately $1 \mathrm{kN}$ (Table 2).

In group I, with cortical fixation, the effects of cement augmentation depth and cortical thickness on pullout force were statistically significant. Cement induced a gain in pullout force of $23 \pm 3 \mathrm{~N}$ per $\mathrm{mm}$ of augmentation $\left(R^{2}>0.72\right)$; the gain due to cortical bone was $200 \pm 25 \mathrm{~N}$ per $\mathrm{mm}$ of cortical thickness $\left(R^{2}>0.76\right)$ (Fig. 4a).

In group II, without cortical fixation, the cortical thickness and augmentation depth had significant effects on pullout force, 

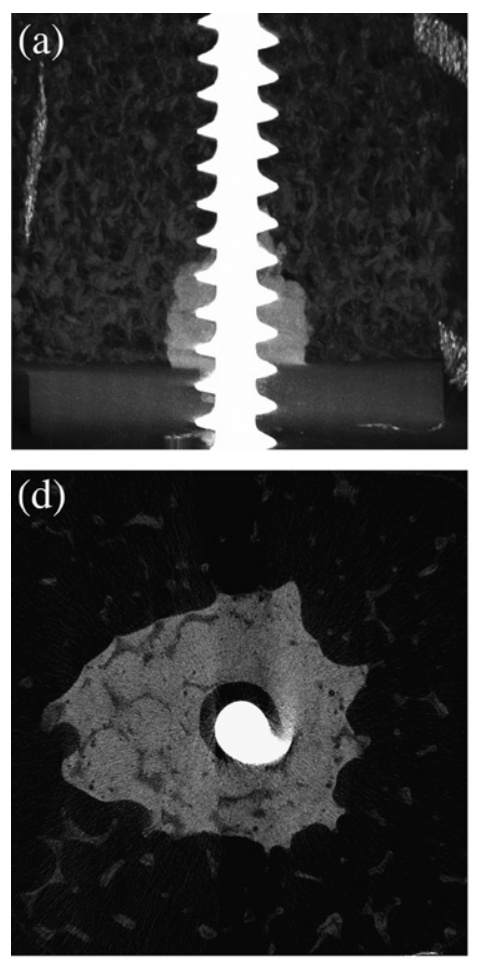

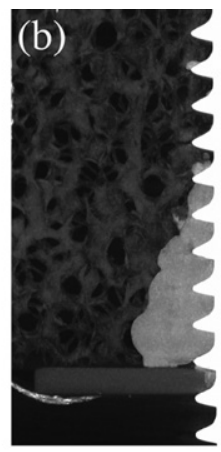

(e)

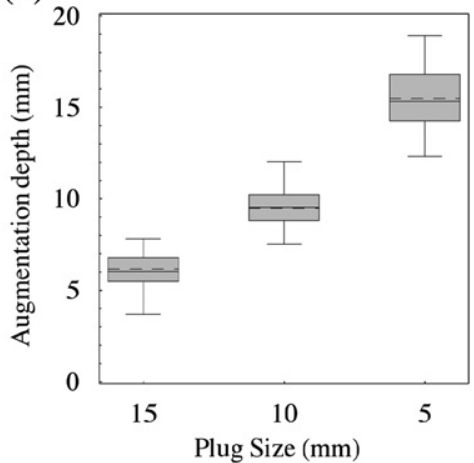

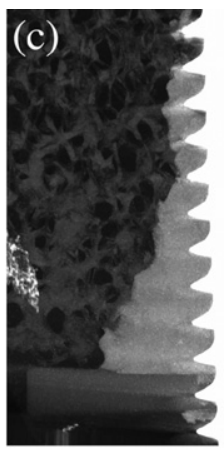

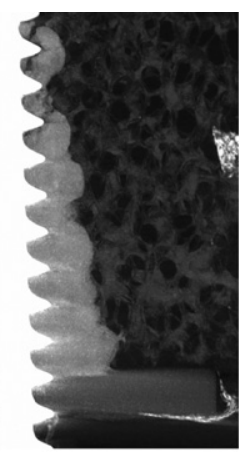

(f)

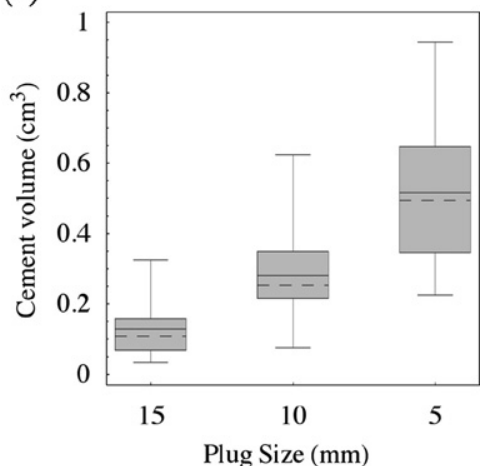

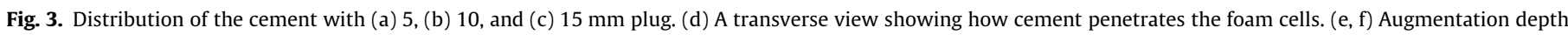
and cement volume distributions for the different plug sizes.

Table 2

Pullout forces. Values are given as MEAN \pm SD.

\begin{tabular}{|c|c|c|c|c|c|c|c|}
\hline \multirow[t]{3}{*}{ Ct.th (mm): } & & \multicolumn{6}{|c|}{ Pullout force $(N)$} \\
\hline & & \multicolumn{3}{|c|}{ (I) With cortical fixation } & \multicolumn{3}{|c|}{ (II) Without cortical fixation } \\
\hline & & 1 & 2 & 3 & 1 & 2 & 3 \\
\hline \multirow[t]{4}{*}{$\mathrm{AD}(\mathrm{mm})$} & $\mathbf{0}$ & $65 \pm 5$ & $229 \pm 10$ & $500 \pm 28$ & $29 \pm 8$ & $32 \pm 7$ & $26 \pm 9$ \\
\hline & 5 & $138 \pm 48$ & $328 \pm 80$ & $533 \pm 62$ & $149 \pm 40$ & $187 \pm 73$ & $129 \pm 64$ \\
\hline & 10 & $226 \pm 76$ & $533 \pm 82$ & $640 \pm 61$ & $186 \pm 86$ & $349 \pm 71$ & $500 \pm 102$ \\
\hline & 15 & $405 \pm 90$ & $546 \pm 100$ & $855 \pm 110$ & $295 \pm 95$ & $594 \pm 150$ & $655 \pm 135$ \\
\hline
\end{tabular}

a

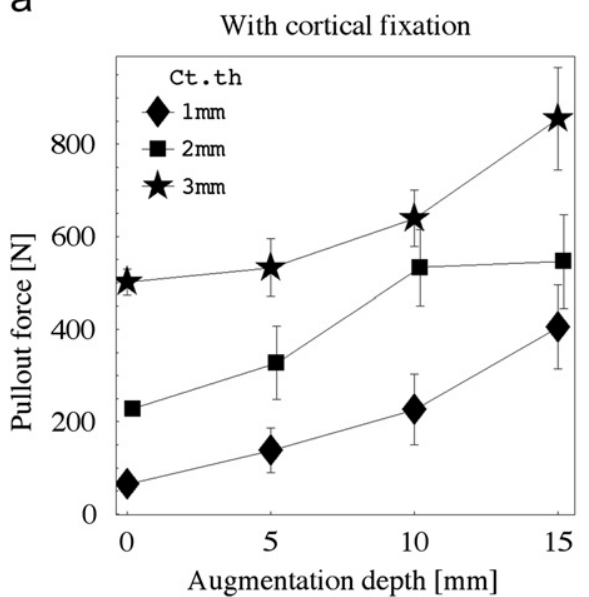

b

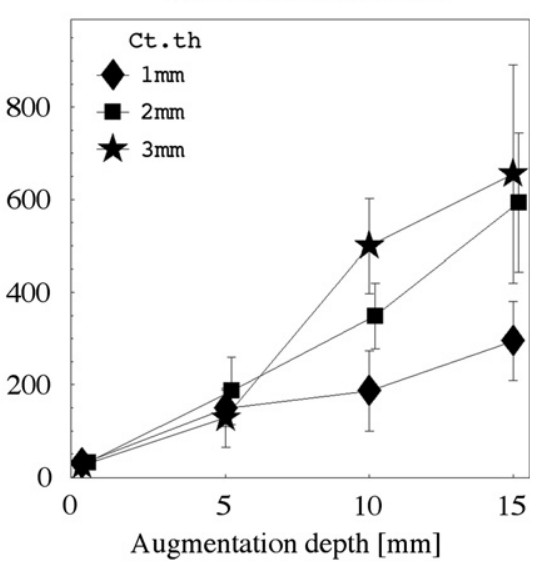

Fig. 4. Pullout forces for each augmentation depth and cortical thickness, (a) without cortical fixation, and (b) with cortical fixation. 
as assessed by ANOVA, but the effects were correlated. The cement induced a gain in pullout force of $17 \pm 3,37 \pm 4$, and $47 \pm 6 \mathrm{~N}$ per mm of augmentation $\left(R^{2}>0.7\right)$ for $\mathrm{ct} \cdot \mathrm{th}=1,2$, and $3 \mathrm{~mm}$, respectively (Fig. 4b).

\subsection{Effect of cortical fixation on pullout force}

The effect of cortical fixation loss can be determined by comparing the pullout forces in group I and II (Table 2). In the non-augmented cases $(A D=0)$, the effect of cortical fixation loss on pullout force was a twofold decrease, seven-folds decrease and sixteenfold decrease, for $\mathrm{ct} . \mathrm{th}=1,2$, and $3 \mathrm{~mm}$, respectively $(p<0.01)$. Cement augmentation significantly reduced these differences. When cortical thickness was not accounted for, the difference between group I and group II was still significant with an augmentation depth of $5(p<0.01)$ but not anymore with an augmentation depth of 10 and $15 \mathrm{~mm}$ (Fig. 5).

\subsection{Failure modes}

We observed that the constructs failed in various modes, but in a remarkably consistent manner: for each group, the same failure mode was observed with $67-100 \%$ prevalence (Table 3 ). In all cases, the foam broke.

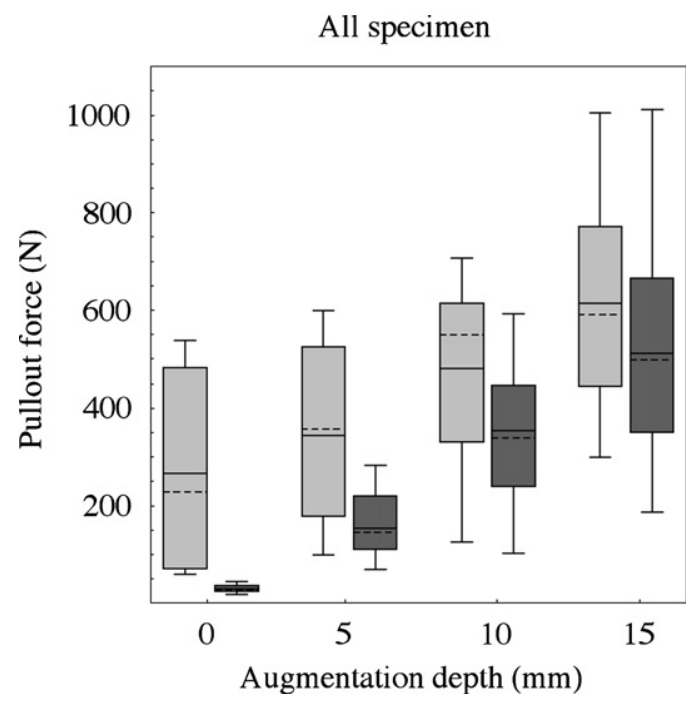

Fig. 5. Pullout force for group I, with cortical fixation (light gray) and group II without cortical fixation (dark gray). The difference is statistically significant for $\mathrm{AD}=0$ and $5 \mathrm{~mm}$ but not for 10 and $15 \mathrm{~mm}$. The augmentation compensates the loss of cortical fixation.

Table 3

Failure modes observed prevalence.

\begin{tabular}{lllllll}
\hline \multicolumn{2}{l}{ Failure modes (prevalence if not 100\%) } \\
\hline Cortical thickness (mm) & Cortical fixation (-) & \multicolumn{4}{l}{ Augmentation depth (mm) } \\
\cline { 3 - 6 } & & $\mathbf{0}$ & $\mathbf{5}$ & $\mathbf{1 0}$ & $\mathbf{1 5}$ \\
\hline $\mathbf{1}$ & yes & R & R & R & R \\
& no & - & C & R & R \\
$\mathbf{2}$ & yes & no & CR1 & CR1 & CR1 \\
3 & yes & - & C & C & C \\
& no & R & CR2 & CR2 & CR2 \\
& & - & C & C & C \\
\hline
\end{tabular}

\section{Discussion}

Augmenting bone with various cements has been shown to be an efficient way to improve the fixation of cancellous bone screws (Benum, 1977; Kawagoe et al., 2000; Mueller, 1962). However, quantitative data about the optimal volume and distribution of cement is not available. In this study, we found that cement augmentation significantly increases the pullout force in all cases. In the groups without cortical fixation the effect of augmentation was correlated with cortical thickness. Cement augmentation increases the screw fixation more when the cortical layer is thicker. When cortical fixation is absent, cement augmentation can compensate for the absence, and the original fixation strength can be restored.

Polyurethane foam and resins have the advantages of being easy to handle and produce very reproducible results; their use is therefore common in orthopedic research (DeCoster et al., 1990; Hearn et al., 1993). The chosen polyurethane foam has a density and mechanical characteristics close to those of osteoporotic bone, and its porous structure is interconnected, which makes it a good model of trabecular bone for cement injection studies (Rovinsky et al., 2000). However no physiological liquids were present in the foam cells, which is likely to permit more cement penetration that would happen in vivo. The effect of different pore sizes of the foam on the augmentation aspect was not evaluated and all the results were obtained with foams presenting similar pore size distribution $(2 \pm 0.5 \mathrm{~mm})$. The resin material has properties close to real cortical shell in human bone (Thompson et al., 2003) and is often used as a model in endodontics (Dummer et al., 1991). It has no apparent porosity, and therefore the interaction with cement is limited. It has to be mentioned that the rate of displacement used in the pullout force was $5 \mathrm{~mm} / \mathrm{min}$. This rate can then be considered as sufficiently low to avoid any significant viscoelastic effects as we previously demonstrated this with even more viscous materials such as ligament and tendons (Pioletti et al., 1998).

The method for the cement insertion has some limitations. The plug system was developed uniquely for this study. It was a practical solution to control the augmentation depth. The timing and temperature of the cement preparation and injection were both critical factors: too slow or too warm would set the cement before the hole is totally filled. The depressor was designed to ensure that cement would perfuse all the way to the plug and as can be seen on Fig. 3, a uniform cement distribution without large pores was obtained.

Ionizing radiations such as X-ray in $\mu \mathrm{CT}$ may affect the mechanical properties of materials and could then influence the value of the pullout force. Nevertheless, in all tested situations, the samples received a similar dose of irradiation, so that if there is any bias present due to the irradiation, this effect will be similar for all specimens.

The main goal of this project was to determine if and how much cement augmentation can improve the screw fixation. We found no condition for which bone augmentation reduces the fixation strength of the screw in the construct. In surgical conditions, the cortical thickness is not a variable that can be controlled but one of the parameters that influence the outcomes of a fracture fixation. Furthermore, in certain conditions, the cortical bone is missing, due to trauma or surgery, and the screw has to be fixed only in trabecular bone. If the bone is weak, cancellous bone alone is likely not to support enough load bearing. The present data suggests that if there is a doubt about the quality of the bone, augmentation is an interesting option to increase the screw purchase.

The correlation between cortical thickness and cement augmentation on pullout strength probably reflects the mechanical role of the cement plug. The cement increases the screw 
purchase in the foam, effectively acting like an increase in screw diameter. But it also creates a link between the screw and the cortical layer. The contact surface between cement and cortical layer is proportional to the augmentation depth due to the pseudo-conic shape of the cement. Given that the cement is stiffer than the foam, the load transmitted through this link must predominate on load gained by the increase in screw purchased. Deeper augmentation thus provides a stronger link to the cortical layer, which can support more load. In the clinical situation, a piece of cortical bone can be missing. Our findings suggest that, to obtain a strong fixation, the larger the missing piece is, the deeper the cement augmentation should be.

\section{Conflict of interest statement}

Procter is an employee of Stryker Osteosynthesis.

\section{Acknowledgements}

This project was supported by the Inter-Institutional Center for Translational Biomechanics EPFL-CHUV-DAL. We thank Stryker Osteosynthesis for generously providing cement and screws for this study.

\section{References}

Bartucci, E.J., Gonzalez, M.H., Cooperman, D.R., Freedberg, H.I., Barmada, R., Laros, G.S., 1985. The effect of adjunctive methylmethacrylate on failures of fixation and function in patients with intertrochanteric fractures and osteoporosis. J. Bone Joint Surg. Am. 67, 1094-1107.

Benum, P., 1977. The use of bone cement as an adjunct to internal fixation of supracondylar fractures of osteoporotic femurs. Acta Orthop. Scand. 48, 52-56.

Chapman, J.R., Harrington, R.M., Lee, K.M., Anderson, P.A., Tencer, A.F., Kowalski, D., 1996. Factors affecting the pullout strength of cancellous bone screws. J. Biomech. Eng. 118, 391-398.

Cook, S.D., Salkeld, S.L., Stanley, T., Faciane, A., Miller, S.D., 2004. Biomechanical study of pedicle screw fixation in severely osteoporotic bone. Spine J. 4, 402-408.
Cowin, S.C., 2001. Bone mechanics handbook. CRC Press, Boca Raton, FL. DeCoster, T.A., Heetderks, D.B., Downey, D.J., Ferries, J.S., Jones, W., 1990 Optimizing bone screw pullout force. J. Orthop. Trauma. 4, 169-174.

Dummer, P.M., Alodeh, M.H., al-Omari, M.A., 1991. A method for the construction of simulated root canals in clear resin blocks. Int. Endod. J. 24, 63-66.

Enis, J.E., McCollough 3rd, N.C., Cooper, J.S., 1974. Effect of methylmethacrylate in osteosynthesis. Clin. Orthop. Relat. Res., 283-294.

Halvorson, T.L., Kelley, L.A., Thomas, K.A., Whitecloud 3rd, T.S., Cook, S.D., 1994 Effects of bone mineral density on pedicle screw fixation. Spine 19, 2415-2420.

Hearn, T.C., Schatzker, J., Wolfson, N., 1993. Extraction strength of cannulated cancellous bone screws. J. Orthop. Trauma. 7, 138-141.

Kawagoe, K., Saito, M., Shibuya, T., Nakashima, T., Hino, K., Yoshikawa, H., 2000. Augmentation of cancellous screw fixation with hydroxyapatite composite resin (CAP) in vivo. J. Biomed. Mater. Res. 53, 678-684.

Kim, W.Y., Han, C.H., Park, J.I., Kim, J.Y., 2001. Failure of intertrochanteric fracture fixation with a dynamic hip screw in relation to pre-operative fracture stability and osteoporosis. Int. Orthop. 25, 360-362.

Larsson, S., 2010. Calcium phosphates. what is the evidence? J. Orthop. Trauma. 24 S41-S46.

Leeson, M.C., Lippitt, S.B., 1993. Thermal aspects of the use of polymethylmethacrylate in large metaphyseal defects in bone. A clinical review and laboratory study. Clin. Orthop. Relat. Res., 239-245.

Mueller, M.E., 1962. Die Verwendung von Kunstharzen in der Knochenchirurgie. Arch. Orthop. Unfall-chir 54, 513-522.

Muhr, G., Tscherne, H., Thomas, R., 1979. Comminuted trochanteric femora fractures in geriatric patients: the results of 231 cases treated with internal fixation and acrylic cement. Clin. Orthop. Relat. Res., 41-44.

Pioletti, D.P., Rakotomanana, L.R., Benvenuti, J.F., Leyvraz, P.F., 1998. Viscoelastic constitutive law in large deformations: application to knee ligaments and tendons. J. Biomech. 31, 753-757.

Rohmiller, M.T., Schwalm, D., Glattes, R.C., Elalayli, T.G., Spengler, D.M., 2002 Evaluation of calcium sulfate paste for augmentation of lumbar pedicle screw pullout strength. Spine J. 2, 255-260.

Rovinsky, D., Haskell, A., Liu, Q., Paiement, G.D., Robinovitch, S., 2000. Evaluation of a new method of small fragment fixation in a medial malleolus fracture model. J. Orthop. Trauma. 14, 420-425.

Seebeck, J., Goldhahn, J., Morlock, M.M., Schneider, E., 2005. Mechanical behavior of screws in normal and osteoporotic bone. Osteoporos. Int. 16 (suppl 2), S107-S111.

Simpson, A.H., Varty, K., Dodd, C.A., 1989. Sliding hip screws: modes of failure. Injury 20, 227-231.

Thompson, M.S., McCarthy, I.D., Lidgren, L., Ryd, L., 2003. Compressive and shear properties of commercially available polyurethane foams. J. Biomech. Eng. 125, 732-734.

Van Landuyt, P., Peter, B., Beluze, L., Lemaitre, J., 1999. Reinforcement of osteosynthesis screws with brushite cement. Bone 25, 95S-98S. 